\title{
UMA EXPERIÊNCIA EM EDUCAÇÃO MATEMÁTICA \\ NO ORIENTE: EDUCADORES PENSANDO MATEMÁTICA NO TIMOR-LESTE
}

\author{
AN EXPERIENCE IN MATHEMATICAL EDUCATION IN THE ORIENT: \\ EDUCATORS THINKING ABOUT MATHEMATICS IN EAST TIMOR
}
UNE EXPÉRIENCE EN ÉDUCATION MATHÉMATIQUE EN ORIENT : ÉDUCATEURS PENSANT LA MATHÉMATIQUE AU TIMOR-EST

\section{UNA EXPERIENCIA EN EDUCACIÓN MATEMÁTICA EN EL ORIENTE: EDUCADORES PENSANDO MATEMÁTICA EN TIMOR-ESTE}

\author{
Cleonice Terezinha Fernandes *, Eliana Moreira **, \\ Luiz Antonio Benardino da Silva ***, Raimundo Santos de Castro ****, \\ Sandra Rodrigues de Sá ${ }^{* * * * *}$, Saulo Furletti ${ }^{* * * * * *}$
}

\section{RESUMO}

O presente relato de experiência trata da descrição da Semana da Matemática, ocorrida no Timor-Leste em 2005. Ela é parte integrante do Projeto Piloto de Capacitação de Professores de Matemática, coordenado pelo Prof. Dr. Chateaubriand Nunes Amâncio, a partir da parceria do World Bank com o Ministério da Educação, Cultura, Juventude e Desporto do Timor-Leste. A essa Semana agregou-se o grupo de professores de Matemática da Missão Brasileira de Cooperação Técnico Educacional/Programa de Capacitação de Docentes e Ensino de Lingua Portuguesa no Timor-Leste. Expressa a visão de tal grupo no contexto da elucidação dos impasses e desdobramentos metodológicos ocorridos durante o evento. Desenvolvida na perspectiva da Educação Matemática, a Semana possibilitou um olhar critico de descobrimento de novas possibilidades, passando a se constituir num referencial para o trabalho que o grupo desenvolverá no Timor-Leste.

Palavras-chave: Educação matemática. Etnomatemática. Psicologia da matemática. Algoritmos diferenciados. Ressignificação de conceitos. Capacitação de professores em exercício.

* Licenciada em Biologia pela Universidade Federal do Mato Grosso; Membro da Comissão Brasileira de Estudos e Pesquisas de Soroban/MEC/SEESP (cleo_terezinha@hotmail.com).

** Licenciada em Matemática pela Universidade de Franca; Bacharelada em Arquitetura e Urbanismo pela Universidade de Mogi das Cruzes (liaarqui@yahoo.com.br).

*** Licenciado em Matemática pela Universidade de Pernambuco; Professor de Matemática da Secretaria de Educação do Estado de Rondônia (luiz_bernardino@yahoo.com.br).

**** Licenciado em Matemática pelo Centro Federal de Educação Tecnológica do Maranhão (raicastro@gmail.com).

***** Licenciada em Matemática pela Universidade Estadual do Rio de Janeiro (sandradesa2000@hotmail.com).

****** Licenciado em Matemática pelo Centro Universitário Belo Horizonte; Especialista em Informática da Educação pela Universidade Federal de Lavras (sfurletti@fastem.com). 


\section{O TIMOR-LESTE E SUA COMPLEXIDADE}

A República Democrática do Timor-Leste (RDTL) consolida-se como a mais nova nação do Século XXI. Reconstruir seu sistema educacional de maneira a possibilitar a afirmação de uma identidade coletiva que considere as demandas do mundo contemporâneo sem, no entanto, deixar de lado sua imensa riqueza cultural é, sem dúvida, um dos mais importantes desafios a serem superados.

Segundo dados do Ministério do Desenvolvimento e Meio-Ambiente da RDTL, o Timor-Leste ocupa uma área de aproximadamente $15.000 \mathrm{~km}^{2}$, e sua população é estimada em 790.000 habitantes. Uma pequena meia-ilha dividida em 13 distritos e o enclave de Oekusi, na metade oeste da ilha do Timor. Seu território é bastante diversificado, com regióes montanhosas, planícies e savanas, selvas, florestas de coqueiros e palmeiras e plantações de arroz. Possui uma imensa riqueza étnico-cultural, e em seu território existem cerca de 33 grupos lingüísticos (TIMOR-LESTE, 2004b).

Em 2002, com a aprovação da Constituição da República Democrática do TimorLeste, as línguas tétum e portuguesa passaram a ser oficiais do país. Para cumprir o que determina a Carta Magna e, conseqüentemente, iniciar a reconstrução de suas bases intelectuais, uma das medidas adotadas foi dar início à implementação da língua portuguesa nas escolas primárias. Neste sentido, o Estado vem empreendendo um enorme esforço para tornar a língua portuguesa, corrente em todos os níveis escolares, uma vez que o tétum, reconhecido como língua mãe, encontra-se em fase de "fortalecimento"; e, na condição de língua primeira, tem muitos termos incorporados da língua portuguesa, durante os mais de 450 anos de colonização portuguesa (1512 a 1975).

É essa nação que quer construir um outro futuro aos seus filhos e reescrever sua história. De acordo com as Resoluções do I Congresso Nacional de Educação, realizado em outubro de 2003 pelo Ministério da Educação, Cultura, Juventude e Desporto (MECJD):

(...) depois do setembro negro de $1999,{ }^{1}$ as infra-estruturas de Timor-Leste foram destruídas, incluindo as infra-estruturas da educação.(...) o ano de 1999/2000² não foi oficialmente considerado ano escolar e quase todos os alunos (com exceção dos de Baucau) automaticamente repetiram um ano. Isto significa que em 2000/2001 o ensino primário teve de dar resposta aos novos alunos e ao grupo dos alunos repetentes do ano anterior.

É importante frisar que a língua portuguesa, língua oficial durante a referida colonização, foi proibida ao longo de toda a ocupação da Indonésia, ou seja, aproximadamente três décadas (1975 a 1999), e apenas o Externato São José a continuou utilizando até 1992.

Assim, todas as ações governamentais referentes à educação convergem para que dentro de pouco tempo todos os professores estejam "habilitados" a ministrar aulas em língua portuguesa, pois os alunos que estão saindo do nível primário para o présecundário, em sua grande maioria, dominam o referido idioma.

Atualmente, o governo, por meio do MECJD, pretende iniciar a adoção da língua portuguesa nas escolas pré-secundárias e secundárias. A política de adoção da língua 
portuguesa pelo Estado timorense é o principal motivo pelo qual está aqui a Missão Brasileira de Cooperação Técnico Educacional no Timor-Leste - Programa de Qualificação de Docentes e Ensino de Língua Portuguesa no Timor-Leste, da qual fazemos parte. A Missão conta com 48 profissionais das áreas de biologia, matemática, química, língua portuguesa e pedagogia. Está prevista uma duração de três anos.

Para a concretização das ações governamentais, faz-se extremamente necessário que os professores dos níveis pré-secundário e secundário tenham o domínio da língua. Esse tem sido o foco das discussões, já que os professores com idade inferior a 35 anos foram formados no período de ocupação indonésio, ou seja, na chamada geração Tim-Tim, ${ }^{3}$ dominam o tétum, bahasa indonésio e o inglês, e entendem precariamente a língua portuguesa. Porém, como já dito anteriormente, o tétum é uma língua que está sendo "fortalecida" e não possui palavras suficientes para sua utilização como língua de instrução, e o bahasa indonésio, de acordo com o Art. 159 da Constituição da RDTL, é considerado língua de trabalho, e não de instrução.

Nesse contexto, a realização de um experimento de "capacitação" de professores de matemática timorenses, constante do Projeto Piloto de Capacitação de Professores de Matemática, desenvolvido a partir da parceria do World Bank, através do FSQP Fundamental School Quality Project e do Ministério da Educação, Cultura, Juventude e Desporto do Timor-Leste, por meio do IFCP - Instituto de Formação Contínua de Professores, constituiu-se, para os cursistas ${ }^{4}$ timorenses, em um exercício prático da língua portuguesa com conteúdos matemáticos, e, para nós, professores de matemática, membros da Missão Brasileira, como desafio e, conseqüentemente, um aprendizado fascinante.

Aprendizado no sentido de descobertas pedagógicas e estratégicas metodológicas de ensino e aprendizagem da matemática, e desafio por termos sidos convidados a fazer parte do projeto na condição de observadores participantes, pelo consultor do FSQP, Prof. Dr. Chateaubriand Nunes Amâncio. ${ }^{5}$ Desafio também porque isto ocorreu imediatamente após a nossa chegada ao Timor-Leste, e por trazermos do Brasil a concepção de que tudo que proporíamos no campo da educação matemática seria fruto de discussões com professores e alunos timorenses e, principalmente, por desconhecermos a fundo aspectos sócio-culturais e políticos que poderiam nos ajudar a melhor compreender o contexto histórico em que o povo e o país se encontram.

Por entendermos que o processo educacional não deve estar dissociado do contexto histórico em que o cidadão está inserido, nossa preocupação se dava em procurar, o mais rápido possível, informações que nos possibilitassem uma maior aproximação com os professores timorenses e com o povo de modo geral. É importante destacar que, mesmo com todo nosso esforço, tínhamos a consciência de que efetivamente isso não se daria em pouco tempo. Entretanto, toda informação possível nos permitiria desenvolver as atividades que nos propusemos a realizar com o mínimo de coerência.

O objetivo principal do Projeto, de acordo com seu relatório final, foi a "verificação da capacidade dos professores em pensar os conteúdos e principalmente os encaminhamentos metodológicos da Matemática quando ministrados em lingua portuguesa" (AMÂNCIO, 2005, p. 8); ou seja, a construção do processo democrático no país passa, também, pela implementação da língua portuguesa, por ter sido, juntamente com o tétum, a língua usual dos membros da resistência à ocupação Indonésia. 


\section{TROCANDO EXPERIÊNCIAS}

Como já exposto, o grupo de professores observadores foi convidado a participar do projeto, sendo que algumas de suas atividades já tinham sido desenvolvidas ou estavam em desenvolvimento. A nossa inserção se deu a partir de uma reunião na sede do IFCP com os professores timorenses, o consultor do World Bank, coordenadores do Instituto e representantes da Missão brasileira, que teve por objetivo proporcionar aos professores cursistas e aos observadores a oportunidade de discutir os conteúdos matemáticos que deveriam ser tratados durante a pilotagem $^{6}$ propriamente dita, sendo que tais conteúdos foram propostos pelos próprios cursistas. Na oportunidade conhecemos certas características do sistema educacional do Timor-Leste, como, por exemplo, os níveis escolares, assim distribuídos: pré-primário (uma classe ${ }^{7}$ ), primário (seis classes), pré-secundário (três classes), secundário (três classes) e terciário (superior, cuja duração varia conforme o curso, oscilando entre três e cinco anos). Seguem dados do MECJD, de abril de 2005 , mostrando um panorama quantitativo da rede pública escolar timorense:

\begin{tabular}{|l|c|c|}
\hline & Professores & Escolas \\
\hline Nível Primário & 4408 & 749 \\
\hline Pré-secunctário & 1155 & 126 \\
\hline Secundário & 613 & 57 \\
\hline Profissionais & 214 & 13 \\
\hline Pré-escola & 70 & 58 \\
\hline
\end{tabular}

Outro aspecto relevante foi descobrirmos, por meio dos relatos dos cursistas, que nas escolas apenas os professores possuem livros e que estes estão escritos em bahasa indonésio. Os atuais alunos dos níveis pré-secundário e secundário, oriundos ainda do ensino em língua indonésia, dominam o bahasa indonésio, o tétum e o inglês, sendo que poucos conseguem entender algumas expressôes em língua portuguesa, já que tal ensino foi implementado a partir das primeiras classes do primário apenas desde 2000/2001.

Tais professores afirmam que em muitos casos são obrigados a ministrar aulas em vários idiomas para se fazerem entender pelos alunos, ou seja, as salas de aula, no caso de matemática, o que não deixa de ser uma realidade para as outras disciplinas, se constituem verdadeiramente em uma "babel lingüística". O que por um lado pode ser difícil para o educando, por outro lado pode propiciar uma abertura epistemológica. A justificativa para essa situação recai no fato de que, em tétum, língua que praticamente todos entendem, não há termos para a simbologia matemática; portanto, se recorre às outras línguas e, em alguns casos, emergencialmente, até à língua portuguesa, apesar do pouco domínio. Seguem alguns termos matemáticos e suas traduçôes nos referidos idiomas (Tab. 1), para que se observe a falta de proposiçôes em tétum para a referida área. 
Tabela I - Ministério da Educação, Juventude e Desporto (MECJD)/Instituto de Formação Contínua de Professores (IFCP).

\begin{tabular}{|c|c|c|c|c|}
\hline SÍMBOLO & INDONÉSIA & PORTUGUÊS & INGLÊS & TÉTUM \\
\hline+ & Tambah, pus,positif & Mais,Adição,Positivo & Adition & \\
\hline- & $\begin{array}{c}\text { Minus, Kurang, } \\
\text { Negatif }\end{array}$ & \begin{tabular}{|c|} 
Menos, \\
Subtração,Negativo \\
\end{tabular} & Subtraction & \\
\hline$x$ & Kali & Vezes, Multiplicação & Multiplication & \\
\hline$-\div 1$ & Bagi, Dibagi, Per & Divisão & Division & \\
\hline$=$ & Sama denga & Igual & Equal & \\
\hline$\neq$ & Tidak Sama & $\begin{array}{l}\text { Não é igual, } \\
\text { Diferente }\end{array}$ & Is not equal & \\
\hline$\%$ & Persen & Percentagem & Percent & \\
\hline$\pi$ & $\operatorname{Pi~}(3.14, \quad)$ & $\mathrm{Pi}(3.14)$ & $\mathrm{Pi}(3.14)$ & \\
\hline r & Jari jari & Raios & Radius & \\
\hline$d$ & Diamater & Diâmetro & Diameter & \\
\hline$P$ & Panjang & Comprimento & Length & \\
\hline 1 & Lebar & Largura & Width & \\
\hline $\mathrm{t}$ & Tinggi & Altura & Heigth & \\
\hline A & Alas & Base & Base & \\
\hline & Segitiga & Triângulo & Triangle & \\
\hline & Persegi & Quadrado & Square & \\
\hline & Persegi panjang & Retângulo & Rectangle & \\
\hline & Kubus & Cubo & Cube & \\
\hline & Balok & Paralelepipedo & $\begin{array}{l}\text { Cuboid or } \\
\text { rectangular prism }\end{array}$ & \\
\hline & Tabung & Cilindro & Cylinder & \\
\hline
\end{tabular}




\section{O GRUPO E SEUS DESAFIOS}

A Missão brasileira chegou ao Timor-Leste no início de abril, e a nossa inserção no Projeto acelerou a necessidade de relatarmos nossas experiências pessoais e os procedimentos metodológicos que cada um adota para o ensino da matemática. Após tomarmos conhecimento dos aspectos do Projeto Piloto e dos relatos dos professores, por meio de uma reunião, todos os participantes do grupo ficaram à vontade para uma apresentação mais aprofundada de suas expectativas e de suas respectivas formas de trabalho. Nesse momento ficou claro que a educação matemática seria o alvo de nossas ações, pois se entendeu que somente educando pela matemática, e não para a matemática, seus conteúdos seriam melhor contextualizados e ressignificados, de maneira a propiciar aos estudantes maior entendimento.

É mister nessa linha pedagógica que o educador atribua a mesma importância a conteúdo, objetivo de ensino e metodologia. Isso requer um nível maior de comprometimento do professor no que tange a planejamento, avaliação e postura em sala de aula.

Constava do Projeto Piloto inicial uma semana de capacitação com os cursistas. Para pensarmos no encaminhamento metodológico da referida semana, ou seja, de fato quais atividades/propostas de trabalho seriam apresentadas como desencadeadoras do desenvolvimento dos conteúdos matemáticos indicados pelos cursistas, optamos por situações de problematizacão/contextualização dos respectivos conteúdos, dentro, portanto, da visão da educação matemática.

Como propor razão, proporção, m.m.c., sem deixá-los soltos, descontextualizados? Essas foram as principais indagações do grupo de observadores participantes, enquanto mediadores da aprendizagem metodológica do grupo de cursistas.

Em que medida propor situações de desconstrução de conceitos, sem nos tornarmos enfadonhos, nem subestimar a capacidade reflexiva do grupo de cursistas, sem incorrer em pré-conceitos pedagógicos?

Baseado nessas reflexões, o grupo de observadores entendeu que deveria propor a denominação de Semana da Matemática, e as questōes expostas foram as principais preocupações quando de sua preparação. Então, optou-se por realizar quatro atividades práticas motivadoras dos conteúdos previamente escolhidos pelo grupo de cursistas. Foram elas: visita a um museu de arte - Arte Moris; confecção de uma maquete do prédio do IFCP; visita a uma feira local; uso de artigos de jornal atuais.

\section{ALTERNATIVAS EM EDUCAÇÃO MATEMÁTICA}

Os propósitos iniciais das atividades eram:

1. Museu Arte Moris - Moris em tétum designa vida. Esse museu é uma alternativa de arte-educação interessante existente na capital Díli. Coordenado por um casal de europeus, que, no entanto, busca fazer uma arte local, congregando jovens talentosos que já têm alguma expressão artística ou desejo de trabalhar com linguagens artísticas. Trabalha com as linguagens cênica, musical, plástica e gráfica, através do oferecimento 
de aulas gratuitas de música, pintura, desenho, óleo sobre tela, teatro. Jovens timorenses têm a oportunidade de vivenciar uma experiência de arte-educação.

Nosso propósito com Arte Moris era justamente trabalhar com as idéias de proporcionalidade, geometria, perspectiva, escala, cores. Mostrar que a matemática deve ser pensada a partir de contextos de aplicação; do cotidiano; e neste aspecto está em todos os lugares. Inclusive naqueles aparentemente inusitados.

2. Confecção da Maquete do IFCP - O Instituto de Formação Contínua de Professores é um espaço também situado na capital do país, Díli, e seu objetivo é oferecer um programa permanente de capacitações para professores da rede pública de todo o Timor. O espaço físico é composto de vários blocos de alvenaria, dispostos irregularmente, aproveitando a geografia do terreno montanhoso de Díli. Espaço profissional onde estão concentrados a maioria dos professores da Missão da Capes, e a totalidade dos propositores deste artigo, neste contexto, os ditos observadores da pilotagem. Nele aconteceu toda a Semana da Matemática. Partimos da observação do espaço físico, de rascunhos da disposição dos blocos, para posterior confecção da maquete utilizando embalagens vazias e sucata.

A intenção com a maquete era discutir tridimensionalidade e seus conceitos (aresta, face, vértice, polígonos e poliedros). Porém, o objetivo era desconstruir a perspectiva euclidiana normalmente apresentada aos alunos de forma teórica e densa em relação à faixa etária a que se destinava a organização/seleção curricular desta pilotagem (normalmente inicia-se com as definiçóes de ponto, reta e plano, a priori, para o aluno apenas memorizar). A partir da maquete, também trabalhar formação de conceitos topológicos/espaciais, geométricos, culminando em conceitos de área, volume, perímetro, partindo da planificação de "sólidos" na tentativa de propor alternativa para fugir dos "modelos" pré-determinados de construção de poliedros.

3. Visita a uma feira local (Mercado de Comoro). Díli tem muitas feiras populares a céu aberto. São grandes comércios, no estilo asiático, onde se compram desde utilidades de limpeza até utensílios domésticos, passando por todo tipo de hortaliças, frutas, verduras, que inclusive ficam no chão, sobre panos e lonas.

O objetivo dessa atividade era trabalhar razão, proporção, porcentagem, frações, retirando situaçōes-problema da própria realidade visitada. Essa atividade acabou não acontecendo, devido ao desdobramento das demais que, não permitiu sequer sua execução.

4. Matéria do Jornal Lia Foun de 8 de maio de 2005. O jornal é editado de maneira bilíngüe: em tétum e português. A matéria selecionada foi escolhida justamente por ter muitos subsídios numéricos, pois se trata da discussão acerca da realidade sócio-econômica timorense em comparação à realidade indonésia e foi escrita por ocasião da visita do presidente da Indonésia ao Timor-Leste.

Salientamos que, além do conteúdo matemático já explicitado anteriormente, nosso objetivo foi explorar, nessa atividade em particular, um pouco mais a língua portuguesa, uma vez que esse era o foco principal da pilotagem.

Segue abaixo o quadro com o seu formato final, retirado na íntegra do Relatório do consultor do World Bank/ FSQP, bem como seus respectivos desdobramentos: 


\section{Semana de matemática}

\begin{tabular}{|c|c|c|}
\hline Atividades & Questões Levantadas & Conteúdos Abordados \\
\hline $\begin{array}{l}\text { Confec o da Maquete do } \\
\text { IFCP }\end{array}$ & $\begin{array}{l}\text { - r ea ocupada pelo Instituto; } \\
\text {-Posicionamento dos edif cios; } \\
\text {-Localiza o espacial. }\end{array}$ & $\begin{array}{l}\text { Dimens es, rea, per metro, classifica o } \\
\text { de poliedros, planifica o, conceitos de } \\
\text { aresta, v rtice, faces, pol gonos, } \\
\text { constru o de poliedros. }\end{array}$ \\
\hline Visita ao Museu Arte Moris & $\begin{array}{l}\text { - Combina o de cores; } \\
\text {-Formas e figuras geom tricas. }\end{array}$ & $\begin{array}{l}\text { Classifica o das cores, disco de cores, } \\
\text { mosaicos, id ias elementares sobre } \\
\text { perspectiva, per metro de pol gonos, } \\
\text { comprimento de circunfer ncia, rea do } \\
\text { c rculo. }\end{array}$ \\
\hline $\begin{array}{l}\text { Artigo do Jornal Lia Foun: } \\
\text { "Dois Pesos uma Medida!" }\end{array}$ & $\begin{array}{l}\text { - Leitura de texto em } \\
\text { portugu s; } \\
\text {-Explora o de dados num ricos } \\
\text { encontrados no texto; } \\
\text {-Compara o entre dados num ricos } \\
\text { relacionados a Timor-Leste e } \\
\text { Indon sia. }\end{array}$ & Fra o, raz o, propor o, percentagem \\
\hline $\begin{array}{l}\text { Livro did tico de Matem tica } \\
\text { em I ngua bahasa }\end{array}$ & $\begin{array}{l}\text { - Como apresentam-se em portugu s } \\
\text { determinados conte dos encontrados } \\
\text { em I ngua bahasa }\end{array}$ & $\begin{array}{l}\text { Conjuntos num ricos, equa o e } \\
\text { inequac es, linguagem dos conjuntos } \\
\text { aplicada solu o de problemas. }\end{array}$ \\
\hline
\end{tabular}

Os conteúdos apontados no quadro possibilitaram o tratamento de assuntos a partir de articulações entre a construção de conceitos, ou, em determinados momentos, desconstrução, e a sistematização dos mesmos em uma linguagem formal. As ações descritas abaixo resultaram dessas articulações:

- construção do número pi, considerando a relação entre comprimento e diâmetro, a partir do uso de cartolina recortada de forma circular e retiradas de medidas usando barbantes;

- construção do conceito de perímetro considerando a soma dos comprimentos dos lados de um polígono, discutindo tal conceito ao tratarmos o comprimento de uma circunferência, desconstruindo a idéia de que circunferência e círculo são termos sinônimos;

- construção do conceito de área de polígonos, também a partir de cartolina, relacionando área com a contagem de quadrados tomados como unidades, levando tal relação ao cálculo da área de um círculo;

- construção do conceito de perímetro de polígonos;

- construção do conceito de fração e as quatro operações fundamentais, considerando a representação visual das mesmas;

- construção do conceito de razão a partir da idéia de comparação, e de proporcionalidade a partir da discussão de igualdade entre razões, bem como as respectivas propriedades envolvidas;

- classificação de poliedros a partir da planificação de sólidos (AMÂNCIO, 2005, p. 12-15).

Tais desdobramentos ocorreram na perspectiva do ensino. Como levar o educando a compreender determinados conceitos e discuti-los com o educador, se não tomando como algo passível de construção e não algo pronto e acabado? 
Então, no desenvolvimento das atividades em si, o grupo foi discutindo seus préconceitos, momento em que nos deparamos com o que o Consultor do FSQP definiu como pontos de fuga:

Durante a Semana da Matemática, ao ser tratado o assunto área do retângulo como sendo o resultado do produto da medida do comprimento (base) pela medida da largura (altura), apresentado como $\mathrm{A}=\mathrm{b} \times \mathrm{h}$, criou-se o impasse quanto ao uso da palavra altura aplicada a uma figura geométrica unidimensional. Nos livros didáticos indonésios, a mesma situação é tratada como luas do persegi panjang, sendo $\mathrm{L}=\mathrm{p} \times \mathrm{l}$, isto é, panjang (comprimento) multiplicado por lebar (largura); entretanto, para os cursistas, era razoável a idéia de altura quando aplicada a triângulo, não encontrando justificativa para tal uso ao serem questionados quanto à unidimensionalidade desse polígono.

Ainda na discussão de conceitos geométricos, surgiram divergências quanto ao uso dos termos aresta e lado. Para os cursistas, eram termos sinônimos, e, para os observadores, havia diferença, uma vez que aresta, argumentavam, aplicava-se apenas a objetos tridimensionais, no sentido de encontro em planos diferentes de duas faces de um poliedro.

Haja vista que boa parte do conhecimento matemático apresentado nos diferentes níveis escolares, incluindo o Superior, tem como essência o tratamento humano dado às questôes relativas ao espaço, essa situação ilustra a estreita ligação entre o tratamento de conceitos matemáticos e a linguagem adotada em situaçôes didáticas (AMÂNCIO, 2005, p. 16).

Os desdobramentos suscitaram reflexões a partir do conhecimento de um algoritmo diferente de decomposição em fatores primos (Fig. 1), conforme segue, comumente utilizado na Indonésia, segundo informação dos cursistas:

Fig. I - Algoritmo da decomposição em fatores primos retirado de livro indonésio da $6^{\mathrm{a}}$. Classe (MULYANA, A.Z. Pintar Berhitung. Matematika. Untuk SD Kelas VI; Berdasarkan kurikulum 1994 yang disempurnakan).
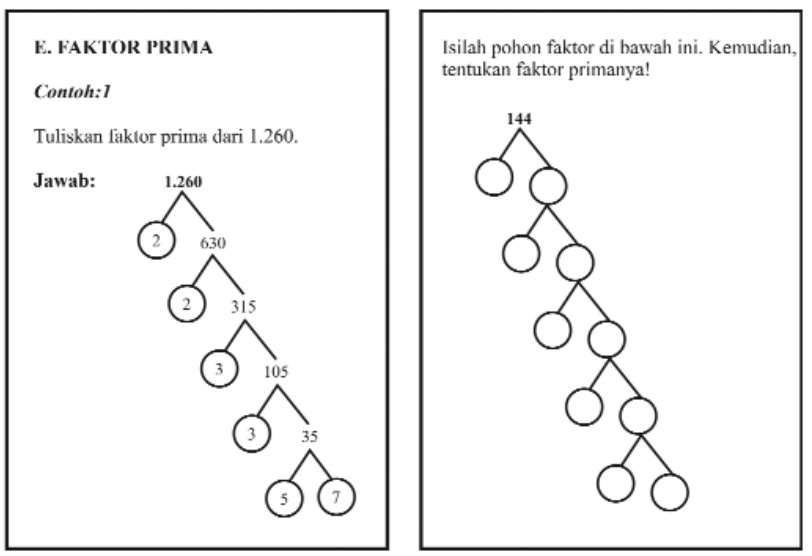
E também um algoritmo indonésio, diferente do ocidental, proposto para divisão:

ALGGORITMO DI DIVISI O UTII.IZADO PARA FNSINAR OS A IUNOS NOTIMOR-I.FSTF(Conforme m?todo indon?'sio)

$312: 23$

Outro fato interessante foi a seguinte discussão: "círculo é um polígono, e como tal poderíamos pensar na definição de perímetro como sendo soma dos lados?" "E agora, onde estão os lados do círculo?” Esta discussão levou a questionamentos interessantes e amadurecimento por parte do grupo de observadores do que seja efetivamente construir conceitos com os alunos.

Também ocorreu conflito na construção do conceito de fração: o confronto com a idéia de divisão de fração, momento no qual nos deparamos com nossa inabilidade coletiva em pensar tal situação concretamente, na perspectiva dos alunos, sem buscar convencê-los pela "matemágica". ${ }^{8}$ Pensar nessa perspectiva é dizer como isso se dá na realidade: por que supostamente uma divisão aumenta o resultado e não diminui como costumeiramente é o ato de dividir? Como mostrar ao aluno a situação de dividir a primeira pelo inverso da segunda fração sem torná-lo um dogma?

Os alunos costumeiramente têm maturidade para essa elaboração teórica? $\mathrm{Ou}$, segundo o Relatório Final do Consultor do FSQP, estamos ajudando a calcificar obstáculos epistemológicos ${ }^{9}$ em nossos alunos quando reproduzimos currículos e conteúdos sem questionar sua pertinência a determinadas faixas etárias.

Outro impasse que vale ressaltar ocorrido entre os grupos foi quanto à proposição da resolução de uma equação na lousa, por parte dos professores timorenses, quando estes não utilizaram o "princípio da economia"10 escrevendo literalmente a "retirada" de um número de um lado da igualdade, através do seu simétrico do outro lado.

As trocas de experiência durante a semana foram muito intensas. O Grupo de observadores participantes, que pretensamente entrou na pilotagem como capacitador, acabou muitas vezes sendo capacitado. A língua foi realmente um empecilho, apesar da presença de tradutores, a ponto de colegas frustrarem-se e solicitarem sua substituição em momentos do encaminhamento metodológico da pilotagem. Todavia, mais do que a língua, a discussão dos conceitos ou pré-conceitos, como aqui pretendemos chamar, foi intensa e desequilibradora para ambos os grupos envolvidos.

Neste momento queremos salientar a presença do Prof. Dr. Chateaubriand Nunes Amâncio, consultor do FSQP, que buscava, numa postura típica da etnomatemática, fazer com que ambos os grupos pensassem na perspectiva um do outro. Perceber que determinados caminhos não são nem melhores, nem piores, mas atendem a distintas situações sócio-culturais, foi um exercício por vezes doloroso e freqüente durante a pilotagem. 
Ficou óbvia a preferência do grupo de cursistas por atividades de resolução de cálculos, por dedução de fórmulas, momentos em que mostravam estar com suas expectativas mais contempladas. Isso ficava notório em suas falas nos momentos da avaliação diária das atividades, ao final de cada tarde. Para a maioria de nós, que tivemos uma formação formalista, adentrar nesse universo pedagógico gera conflitos internos e intensa desequilibração. Observou-se que grande parte dos cursistas possuía domínio do conteúdo matemático proposto: "Matemática eu sei. O que não sei é português"."

Nesse aspecto, vale dizer que muitos observadores ficaram inseguros a respeito da aceitação por parte do grupo de cursistas; muito embora entendamos que não só no Timor-Leste, mas em nossa prática cotidiana, ainda ficamos inseguros de certa forma, mediante críticas ao nosso saber/fazer matemático questionado ao nível do domínio do universo "matematiquês." 12

Ir ao quadro e dar um "show de matematiquês", propondo galantemente elegantes construçôes simbólicas, nos dá mais notoriedade do que partirmos de elaborações pedagógicas com nosso aluno; especialmente se esse "aluno" é um adulto e professor de matemática de um outro país, e que construirá uma imagem de cada um de nós a partir desse encontro.

Durante toda a pilotagem, foram confeccionados cartazes para trabalhar os termos em língua portuguesa, com o intuito de servir de subsídio para os professores timorenses no retorno do próximo semestre letivo, lembrando que a maioria deles não domina a língua portuguesa com fluência.

\section{CONCLUSÃO}

Essa pilotagem representou muito para o grupo de educadores matemáticos da Missão brasileira no Timor-Leste, principalmente por ter permitido experienciar uma atividade que serviu de pré-estréia ao nosso trabalho efetivo dentro da missão Capes nesse país.

Ao termos esse contato prévio e experimental, entramos com uma vantagem nessa querela que é o ensino da matemática para crianças e adolescentes que estão inseridos numa cultura cuja valoração escolar está sendo construída; sequer há interesse em aprender a língua portuguesa por parte da geração que não a domina. Tal vantagem refere-se justamente à experiência e construção do $\operatorname{Ethos}^{13}$ do grupo.

Ao final da Semana da Matemática, o grupo de cursistas formalizou solicitação ao MECJD do Timor-Leste, para que houvesse mais capacitações dessa natureza, e que as mesmas tivessem uma continuidade, além de outras reivindicações de ordem políticopedagógicas bastante coerentes e que traduzem a preocupação do grupo com a qualidade da aprendizagem e do ensino da matemática em seu país.

Após a realização da semana, ocorreu um importante afastamento temporal para uma avaliação menos passional, e nos foi informado, pela Senhora Manuela Gusmão, Coordenadora do IFCP, que os nove professores timorenses participantes da pilotagem não são típicos professores de matemática do Timor-Leste. Foram escolhidos justamente para fazer parte do projeto por terem domínio do conteúdo matemático e, se necessário for, eventualmente, trabalhar como multiplicadores. Segundo a referida 
coordenadora, o universo de professores matemáticos do Timor-Leste não tem domínio conceitual da matemática, o que tem se verificado pelo escore zero (0) dos alunos nos exames nacionais, bem como nos exames de avaliação dos órgãos oficiais de cooperação internacional como ONU e Unicef.

\section{Notas}

1. Em setembro de 1999, após o referendo de 30 de agosto que possibilitou a retomada da independência, grupos de milícias armadas pró-Indonésia e membros do exército indonésio assassinaram centenas de timorenses, saquearam, depredaram e incendiaram aproximadamente 800 edifícios, dos quais $90 \%$ eram escolas; momento em que ocorreu a intervenção militar da ONU mantida até os dias atuais.

2. O ano escolar no Timor-Leste é o mesmo utilizado em alguns países europeus como, por exemplo, Portugal.

3. Abreviatura do termo Timor-Timur; nome indonésio com o qual o Timor-Leste foi rebatizado durante o referido período.

4. Denominaçāo dada no Relatório Final do Projeto aos professores timorenses participantes da capacitação.

5. Short-term Consultant for ESQP; Professor do Programa de Pós-Graduação em Ensino de Ciências Naturais e Matemática do Departamento de Matemática do Centro de Ciências e Tecnologia da Universidade Federal de Roraima.

6. Termo do consultor para designar a ação concreta/execução de um Projeto Piloto (Capacitação).

7. Classe no Timor-Leste, tem o mesmo sentido de seriação no Brasil (1 ano).

8. Termo aqui empregado para designar atitudes de docentes que lançam mão de truques e macetes deixando assim de aprofundar conceitos e definiçôes.

9. Segundo o Vocabulário Auxiliar constante do Relatório Final do ESQP: "A palavra obstáculo (...): trata-se de um impedimento que impossibilita definitiva ou temporariamente a efetuação de algo. Epistemologia, por sua vez, propomos como teoria do conhecimento humano. Conclui-se que obstáculo epistemológico, neste contexto, é a instalação momentânea, que pode vir a ser duradoura, dependendo de nossa atuação, de uma incapacidade em lidar com uma situação que envolve o conhecimento no sentido do saber/fazer compreender" (p. 24).

10. Expressão usada pelo Consultor do FSQP, atribuída ao matemático português Bento de Jesus Caraça, definida como Princípio Geral da Economia de Pensamento. Neste caso, especificamente, foi usada para designar abreviaçōes algorítmicas.

11. Professor Celestino Gusmão, um dos cursistas da Semana da Matemática.

12. Termo designado para exemplificar vocabulário "matemático" pretensamente técnico e rebuscado.

13. Características pessoais de cada um que determinam quais virtudes e quais vícios cada um é capaz de praticar. Refere-se, portanto, ao senso moral e à consciência ética individuais (CONVITE À FILOSOFIA, 2005).

\section{Referências}

AMÂNCIO, Chateaubriand Nunes. Relatório Educação Matemática em Timor-Leste. Fundamental School Quality Project/MECJD Timor-Leste, 2005.

BASSANEZI, Rodney. Introdução à modelagem matemática. Relatório Técnico do IME, Campinas: Unicamp, 1999. 
CHAUI, Marilena. Convite à filosofia. São Paulo: Ática, 2000.

BROUSSEAU, G. Os diferentes papéis do professor. In: PARRA, C. (Org.). Didática da matemática: reflexões psicopedagógicas. Porto Alegre: Artes Médicas, 1996, p..

CARRAHER, Terezinha; SCHLIEMANN, Ana Lúcia; CARRAHER, David. Na vida dez, na escola zero. 12. ed. São Paulo: Cortez, 2001.

CONVITE À FILOSOFIA - Sítio de Filosofia. Disponível em: http://geocities.yahoo.com.br/mcrost02/index.htm. Acesso em: 05 jun. 2005.

D’AMBROSIO, Ubiratan. Etnomatemática. São Paulo: Ática, 1998.

. Da realidade à ação: reflexões sobre educação matemática. Campinas: Summus, 1986.

Educação para uma sociedade em transição. São Paulo: Papirus, 1999.

Transdisciplinaridade. São Paulo: Palas Athena, 1997.

IFRAH, Georges. Las Cifras: historia de una gran invención. Alianza Editorial, 1998.

KAMII, Constance. A criança e o número. São Paulo: Papirus, 1987.

KLINE, Morris. O fracasso da matemática moderna. São Paulo: Ibrasa, 1996.

LAKATOS, Eva; MARCONI, Marina. Metodologia do trabalho científico. 6. ed. São Paulo: Atlas, 2001. . Fundamentos de metodologia cientifica. 3. ed. São Paulo: Atlas, 1991.

MACHADO, Nilson José. Matemática e realidade. São Paulo: Cortez, 1987.

MULYANA, A. Z. Pintar Berhitung. Matematika. Untuk SD Kelas VI; Berdasarkan kurikulum 1994 yang disempurnakan.

PARRA, C. et al. Didática da matemática. Porto Alegre: Artes Médicas, 1996.

PINTO, Neuza B. O erro como estratégia didática: estudo do erro no ensino da matemática elementar. Campinas: Papirus, 2000.

PIAGET, Jean. Fazer e compreender. São Paulo: Melhoramentos, 1978.

PITOMBEIRA, João. Avaliação e perspectivas da área de ensino de Matemática no Brasil. Em Aberto, Brasília, n. 62, p. 74-88, 1994.

PIRES, C. M. C. Currículos de matemática: da organização linear à idéia de rede. São Paulo: FTD, 2000.

REVISTA VISÃO - SUPLEMENTO ESPECIAL: edição comemorativa da Independência do Timor-Leste. n. 480, 16 maio 2002.

SOCIEDADE BRASILEIRA DE EDUCAÇĀO MATEMÁTICA - SBEM. Página institucional. Disponível em: http://www.sbem.com.br. Acesso em: 30 maio 2005.

THOMAZ, Luís Filipe F. R. Babel Loro Sa`e - O problema lingüistico de Timor-Leste (Coleção Cadernos Camões). Lisboa: Instituto Camões, 2002.

TIMOR-LESTE. Constituição da República Democrática do Timor-Leste, 2002.

. Ministério da Educação, Cultura, Juventude e Desporto. Currículo do Ensino Primário - Programa de Matemática, $2004 a$.

- Ministério da Educação, Cultura, Juventude e Desporto. Resoluções do I Congresso

Nacional de Educação, 2003.

- Ministério da Educação, Cultura, Juventude e Desporto. Projeto de (Re)estruturação do Instituto de Formação Contínua de Professores, 2005.

. Ministério do Desenvolvimento e do Meio Ambiente. Secretaria de Estado do Turismo,

Ambiente e Investimento. Descubra a mais nova nação do mundo. CD-Rom Multimídia.

Concepção: Faculdade de Arquitetura da Universidade Técnica de Lisboa, 2004b.

VELADAS, Antonio. Timor: terra sentida. Bilíngüe. Lisboa: Publicações Europa-América, 2001. 


\title{
An experience in mathematical education in the orient: educators thinking about mathematics in East Timor
}

\begin{abstract}
This report is a description of the experience of the Mathematics Week held in East Timor in 2005. The experience was part of a Pilot Project for Mathematics Teachers Training, coordinated by Chateaubriand Amancio, in partnership established between the World Bank and East Timor Ministry of the Education, Culture, Sport and Youth. The teachers of the Brazilian Mission for Technical and Educational Cooperation of East Timor along with the Program for Teachers Training and Portuguese Language Teaching joined in the organization of this Week. It expresses the view of such a group, in the context of elucidating the deadlocks as well as the methodological aftermaths. Developed in the perspective of Mathematical Education, the Week allowed for a critical view of the discovery of new possibilities, thus turning into a reference point for the work that the group of teachers sponsored by Capes will develop in East Timor.
\end{abstract}

Keywords: Mathematical education. Ethnomathematics. Psychology of mathematics. Differentiated algorithms. Concepts renewal. On the job teachers training.

\section{Une expérience en éducation mathématique en orient : éducateurs pensant la mathématique au Timor-Est}

Résumé

Le rapport décrit la Semaine de la Mathématique que sest réalisée au Timor-Est en 2005. Cette expérience fait partie du Projet de Formation de Maîtres de Mathématique, coordonné par Chateaubriand Amâncio, à partir d'un accord de la Banque Mondiale avec le Ministère de l'Éducation, Culture, Jeunesse et Sports de Timor-Est. À cette Semaine sest joint un groupe de professeurs de Mathématique de la Mission Brésilienne de Coopération Technique Éducationnelle du Timor-Est/ Programme de Formation de Maîtres et Enseignement de la Langue Portuguaise au Timor-Est. Il exprime la vision de ce groupe, dans le contexte d'élucider les impasses méthodologiques qui se sont déroulées. Développée dans la perspective de l'Éducation Mathématique, la Semaine a permis un regard critique de découverte de nouvelles possibilités, passant à se constituer en référentiel pour le travail que le groupe de professeurs de la Capes va développer au Timor-Est.

Mots clefs : Éducation mathématique. Ethnomathématique. Psychologie de la mathématique. Algoritmes différentiés. Réssignification de concepts. Formation de maîtres en service.

\section{Una experiencia en educación matemática en el oriente: educadores pensando matemática en Timor-Este}

Resumen

El relato de experiencia trata de la descripción de la semana de la matemática, ocurrida en Timor-Este en 2005. Esta es parte integrante del proyecto piloto de capacitación de profesores de matemática, coordinado por Chateaubriand Amâncio, a partir de la parcería del World Bank con el Ministerio de la Educación, Cultura, Juventud y Deporte de Timor-Este. A esta semana fue agregado el grupo de profesores de matemática de la misión brasileña de cooperación técnico-educacional de Timor-Este/Programa de capacitación de docentes y enseñanza de lengua portuguesa en Timor-Este. Expresa la visión de este grupo en el contexto de la elucidación de los impases metodológicos ocurridos. Desarrollada en la perspectiva de la educación matemática, la semana posibilitó una mirada critica sobre el descubrimiento de nuevas posibilidades, constituyéndose en un referencial para el trabajo que el grupo de profesores de la Capes desarrollará en Timor-Este.

Palabras-clave: Educación matemática. Etnomatemática. Psicologia de la matemática. Algoritmos diferenciados. Resignificación de conceptos. Capacitación de profesores en ejercicio.

Recebido: 06.06 .2005

Aceito: 20.09 .2005 